The occurrence of headache triggered by bath (bath-related headache - BRH -) is rare. The first reference in the literature is of three middle-aged Japanese patients who, in 1992, developed symptoms of abrupt headache onset, of explosive and violent characteristic, caused by drop of hot water over the body in the shower which persisted for several weeks and resolved ${ }^{1}$.

All the cases reported in the literature occurred in Asian populations ${ }^{1,2}$, and there is a unique report on a Spanish woman ${ }^{3}$. We present a case of a Brazilian patient with no Asian ancestry.

Fifty-one-year-old woman, born and resident in Recife, Brazil, with no previous episodes of headache, had nicotine dependence and started varenicline, that was interrupted 30 days after two weeks of use.

The first episode occurred during the bath: sudden and very intense pain reaching the maximum power from the beginning. She described it as if something was to break the skull, and adjectives of "volcanic" and "cosmic" pain were expressed. She localized it on the "top of the head", bilaterally at the frontoparietal region. It lasted about 30 minutes slowly regressing, but persisting with mild intensity during the rest of the day. The response to analgesics was poor. Clinical exam was normal. MRI and arteriography ruled out the possibility of subarachnoid hemorrhage.

She evolved with daily crises, triggered by the water as it contacts the head. She began to avoid showering, fearing recurrence. Last episode occurred approximately 15 days after onset and, to date, she had no further crisis.
The contrast between the nature of an excruciating pain and the triggering of a so routine and trivial act is at least intriguing. The physicians themselves, facing this unusual situation and the picturesque character of the trigger, may tend to underestimate the condition and minimize it to a mere psychogenic conditioning factor.

It is assumed that BRH is a variant of idiopathic thunderclap headache, which may also have as a trigger a variety of factors, such as the Valsalva maneuver, sexual intercourse or strenuous exercise ${ }^{4}$. Etiopathogenic hypotheses involve excessive stimulation of temperature receptors in the skin and scalp and exaggerated autonomic neurovascular reflex, resulting in reversible cerebral vasoconstriction ${ }^{4}$.

The pathogenic role of varenicline as a partial nicotinic cholinergic agonist is questioned. This is a new drug that includes in its side effects profile the onset of mild to moderate headache in $10.3 \%^{5}$. Although the symptoms occurred one month after it was discontinued, its participation cannot be completely rule out, since central nicotinic receptors have a role in brain vasoregulation.

The occurrence of BRH only in the Asian population was intriguing, but the report of this case and another one alike in this west part of the world ${ }^{3}$ indicates that ethnic factors perhaps are not so decisive, and a universal occurrence would most likely exist. The disclosure of new cases may lead to a better nosological and etiopathogenic definition in the future.

\title{
References
}

1. Negoro K, Morimatsu M, Ikuta N, Nogaki H. Benign hot bath-related headache. Headache 2000;40:173-175.

4. Solomon S, Dodick DW. Bathing headache: a variant of idiopathic thunderclap headache. Cephalalgia 2003;23:853

2. Wang SJ, Fuh JL, Wu ZA, Chen SP, Lirng JF. Bath-related thunderclap headache: a study of 21 consecutive patients. Cephalalgia 2008;28:524530

3. Rossi P, Nappi G. Bath-related headache: the first European case. Cephalalgia 2006;26:1485-1486

5. Nakamura M, Oshima A, Fujimoto Y, Maruyama N, Ishibashi T, Reeves KR. Efficacy and tolerability of varenicline, an alpha4beta2 nicotinic acetylcholine receptor partial agonist, in a 12-week, randomized, placebo-controlled, dose-response study with 40-week follow-up for smoking cessation in Japanese smokers. Clin Ther 2007;29:1040-1056.

\section{Medulla compression caused by vertebrobasilar dolichoectasia}

\section{Compressão medular causada por dolicoectasia vertebrobasilar}

\author{
Pedro Enrique Jiménez Caballero', Ignacio Casado Naranjo²
}

${ }^{1}$ Facultativo Especialista en Neurología, Departamento de Neurología, Hospital San Pedro de Alcántara, Espanha;

2Jefe de Sección, Departamento de Neurología, Hospital San Pedro de Alcántara, Espanha.

Correspondence: Pedro Enrique Jiménez Caballero; Departamento de Neurología; Hospiral San Pedro de Alcántara; Avenida Pablo Naranjo s/n; 10003

Cáceres - Espanha; E-mail: pjimenez1010j@yahoo.es

Conflict of interest: There is no conflict of interest to declare.

Received 10 November 2011; Received in final form 09 December 2011; Accepted 16 December 2011 
Vertebrobasilar dolichoectasia (VBD) is a distinct arteriopathy characterized by elongation and dilatation of basilar and vertebral arteries. Prevalence is estimated to be $0.05 \%^{1}$.

VBD may be asymptomatic or associated with clinical manifestations, such as posterior circulation stroke, intracranial bleeding, cranial nerve disorders, compression of brainstem or obstructive hydrocephalus ${ }^{2}$. Medullary compression by the vertebral artery (VA) is a little known clinical entity in the medical literature.

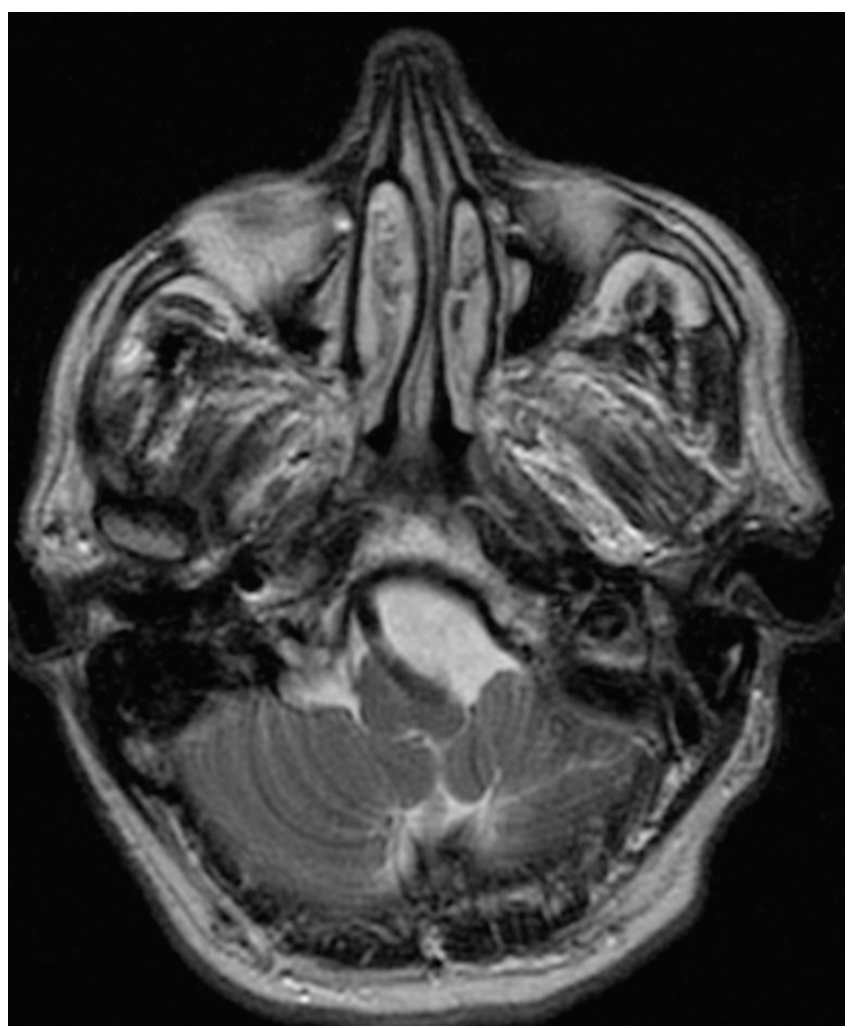

Fig 1. Brain MRI (T2-weighted axial section) revealing a dolichoectactic left-sided vertebral artery with impingement of the left ventrolateral medulla surface.

\section{CASES REPORT}

A 53-year-old man presented to our outpatient department with complaints of slurring of speech and dizziness with imbalance while walking since eight months. He had not risk factors and was ruled out polycystic kidney disease. On examination, he had left Horner syndrome, dysarthria, mild left limb ataxia and bilateral pyramidalism with right babinsky sign. Brain magnetic resonance imaging (MRI) with angiography (Fig 1 and 2) revealed

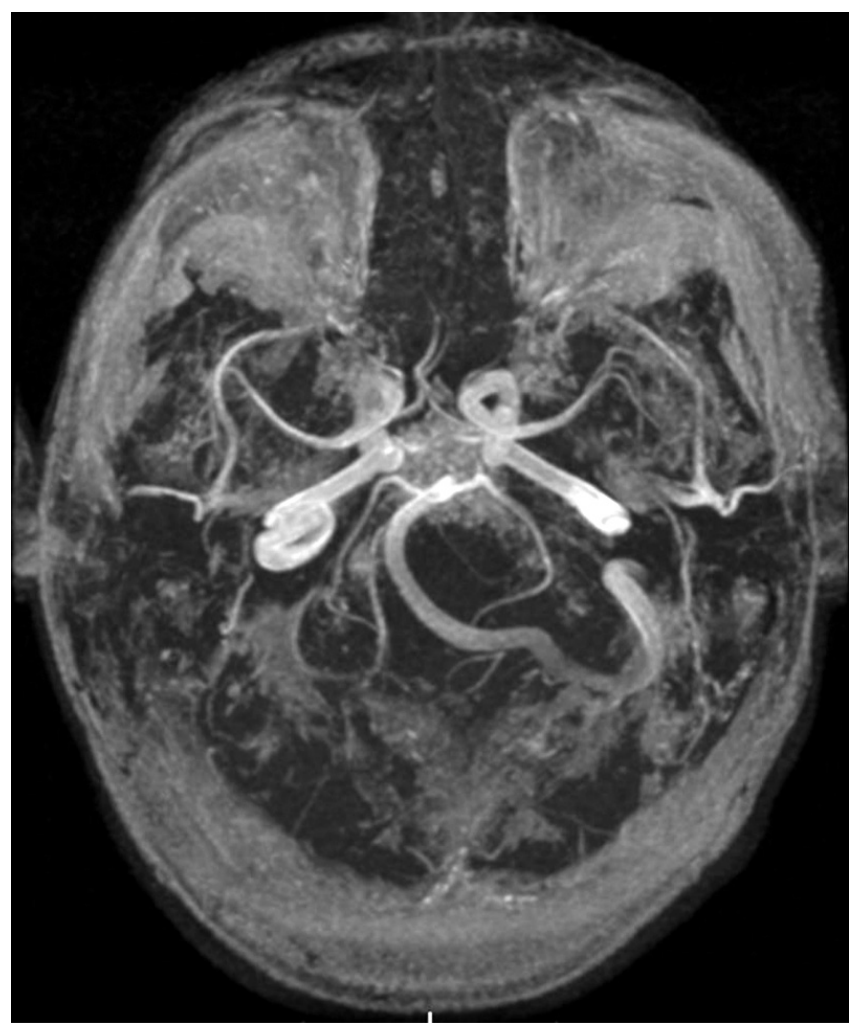

Fig 2. Magnetic resonance angiography showing left vertebral artery with enlargement diameter and tortuous journey.

\section{References}

1. Caplan LR. Dilatative arteriopathy (dolichoectasia): what is known and not known. Ann Neurol 2005;57:469-471.

2. Passero SG, Rossi S. Natural history of vertebrobasilar dolichoectasia. Neurology 2008;70:66-72.

3. Savitz SI, Ronthal M, Caplan LR. Vertebral artery compression of the medulla. Arch Neurol 2006;63:234-241.
4. Gutierrez J, Sacco RL, Wright CB. Dolichoectasia - an evolving arterial disease. Neurology 2011;7:41-50.

5. Gupta D, George UB, Pandian JD. Vertebrobasilar dolichoectasia and a tale of two brothers. Neurol India 2010;58:810-812. 